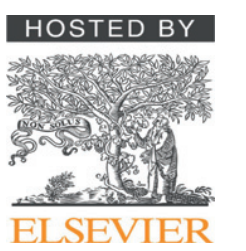

Short communication

\title{
Percutaneous ASD and VSD closure of 4-month-old infant in the same session
}

\author{
Nazmi Narin, Ozge Pamukcu*, Ali Baykan, Suleyman Sunkak, Kazim Uzum \\ Pediatric Cardiology Department, Faculty of Medicine, Erciyes University, 38350 Kayseri, Turkey
}

\section{A R T I C L E I N F O}

\section{Article history:}

Received 17 July 2015

Received in revised form 5 October 2015

Accepted 6 October 2015

Available online 18 October 2015

\section{Keywords:}

ASD

VSD

Infant

Percutaneous

Closure

\begin{abstract}
A B S T R A C T
Percutaneous closure of septal defects is a successful treatment modality that has been used for a long period of time in children.

Our main objective in this case report is to discuss the transcatheter closure of atrial and ventricular septal defects of 4-month-old infant in the same session. As far as we know, this case is the smallest one in age that percutaneous VSD closure was done in the same session with ASD closure.

A 4-month-old boy with tachypnea, tachycardia diagnosed to have aneursymatic perimembranous ventricular septal defect (VSD) sized $4 \mathrm{~mm}$ and atrial septal defect (ASD) sized $8 \mathrm{~mm}$. Anti-congestive treatment was started, but despite to the treatment, his symptoms continued and he was hospitalized 3 times for lower respiratory tract infections. Surgery was found as too risky because his lung parenchyma was not good and body weight was low. Therefore, transcatheter closure was planned. VSD was closed with $4 \times 4$ Amplatzer ${ }^{\circledR}$ Ductal Occluder II device, ASD with $9 \mathrm{~mm}$-sized Amplatzer® Septal Occluder. In his first month control: his body weight increased to $6.2 \mathrm{~kg}$. In conclusion, percutaneous ASD, VSD closure is being done safely in children, but for the first time, percutaneous VSD closure was done in an infant with low body weight in the same session with ASD closure successfully. This case will be an encouraging example for the future.

(C) 2015 The Society of Cardiovascular Academy. Production and hosting by Elsevier B.V. All rights reserved. This is an open access article under the CC BY-NC-ND license (http://creativecommons.org/licenses/by-nc-nd/4.0/).
\end{abstract}

\section{Introduction}

Percutaneous closure of septal defects is a successful treatment modality that has been used for a long period of time in children.

Our main objective in this case report is to discuss the transcatheter closure of atrial and ventricular septal defects of a 4-month-old infant in the same session. As far as we know, this case is the smallest one in age that percutaneous VSD closure was done in the same session with ASD closure, except hybrid procedures.

\section{Case report}

A 4-month-old boy; weighing $4.6 \mathrm{~kg}$, was referred to our clinic for the heart murmur. He suffered from having frequent lower respiratory tract infections. His weight gain was insufficient. He had tachypnea (68/min), tachycardia (150/min), and $2-3^{\circ} / 6$ pansystolic murmur in his physical examination. Aneurysmatic perimembranous ventricular septal defect (VSD) sized $4 \mathrm{~mm}$ and atrial septal defect(ASD) sized $8 \mathrm{~mm}$ (Fig. 1) were detected by transthoracic echocardiography. Anti-congestive treatment was started, but despite the treatment, his symptoms continued

\footnotetext{
* Corresponding author at: Div. Pediatric Cardiology, School of Medicine, Erciyes University, 38350 Kayseri, Turkey.

E-mail address: ozgepamukcu2002@yahoo.com (O. Pamukcu).

Peer review under responsibility of The Society of Cardiovascular Academy.
}

and he was hospitalized 3 times for lower respiratory tract infections. Also, bilateral renal calculi were found in abdominal ultrasonography.

Surgical closure of septal defects was planned, but since the lung parenchyma was not good and his body weight was low, it was accepted as too risky. Therefore, transcatheter closure was planned. Qp/Qs ratio was measured as 4, pulmonary artery pressure was $37 / 10$ mean $29 \mathrm{~mm} \mathrm{Hg}$. VSD was closed with $4 \times 4$ Amplatzer ${ }^{\circledR}$ Ductal Occluder II device, ASD with 9 mm-sized Amplatzer® Septal Occluder (Figs. 2, 3). The VSD was passed through by using a right Judkins catheter or a partly cut pigtail catheter. A hydrophilic glide wire was passed across the defect into the right ventricle and then into the pulmonary artery or superior vena cava, where it was snared and withdrawn from the femoral vein thus establishing an arteriovenous loop. Subsequently, a sheath was advanced to the left ventricle via the arteriovenous circuit. An occluder was advanced into the delivery sheath. Then the occluder was positioned on the VSD. Intervention was guided transthoracic echocardiography in addition to floroscopy.

We have been following the patient for 1 year. We have seen him firstly 1 week later on; 1 month, 3 months, 6 months after the procedure. Each time we did his physical examination, checked his electrocardiogram, and controled valvular insufficiency and device position with transthoracic echocardiography, we have not faced with any problem even the vascular ones. In his first month control, his body weight increased to $6.2 \mathrm{~kg}$, his cardiac functions were normal, no residual shunt was detected in echocardiographic examination. We also were not faced with conduction problems like AV block. 


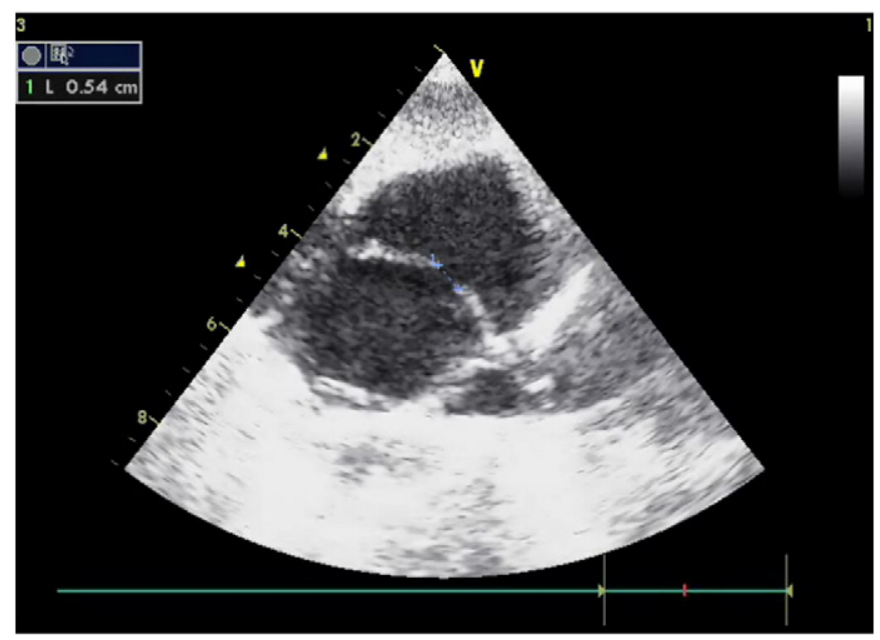

Fig. 1. Echocardiographic image of ASD.

\section{Discussion}

Large atrial septal defects may lead to congestive heart failure, frequent respiratory infections, and growth retardation in infants. ${ }^{1}$

Also ventricular septal defects that have significant shunt, increase pulmonary blood flow, enlarge the left chambers of heart, cause cardiac dysfunction, arrhythmia and constitute a risk factor for infective endocarditis.

Surgical closure of septal defects is gold standard, it is safe and effective; however, the morbidity associated with sternotomy/thoracotomy, cardiopulmonary bypass, postoperative complications, and residual surgical scarring cannot be avoided.

Transcatheter closure of perimembranous VSDs constitutes special care because of greater technical difficulty arising from proximity to the aortic valve and conduction tissue. In order to minimize such risks; appropriate device should be selected according to the type, location, and the size of the defect. Amplatzer ${ }^{\circledR}$ Ductal Occluder (ADO) is actually designed for ductal closure. As we mentioned in previous studies, shape of aneurysmatic VSD resembled PDA. Therefore, it makes closure of VSD with septal aneurysm possible with the Amplatzer duct occluder. The left ventricular margin of the VSD is larger than the right one. The left ventricular margin resembles the aortic side and ampulla of a PDA while the right ventricular margin and septal aneurysm resemble the

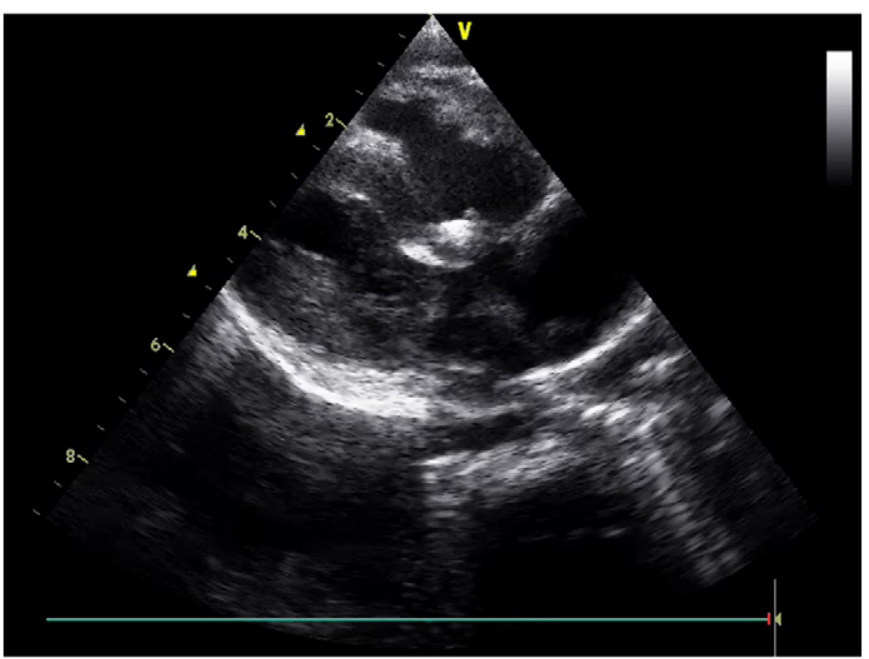

Fig. 3. Echocardiographic image of VSD after closure with ADO II device.

narrowing of a PDA at the pulmonary artery margin. ${ }^{2}$ The design of the ADO II device is soft in nature with no polyester material that does not apply a direct force on conduction system. We have done 21 VSD closures with ADO II device in 3 years interval in our institution. We did not face with any complication and our success rate was $100 \%$.

ADO II device are normally contraindicated in the patients less than $6 \mathrm{~kg}$ and less than 6 months of age. But it is frequently used for PDA closure for newborns less than $6 \mathrm{~kg}$. We have not faced with a case less than $6 \mathrm{~kg}$ whose VSD was closed percutaneously in the literature.

New advances in pediatric cardiology enable us to apply interventions safely and effectively to the younger patients even the newborn. Interventions to multiple defects in the same session is a tough issue in children. More common usage of combined transcatheter procedures, lessened the ratio of surgery needed cardiac lesions and decreased the mortality and morbidity related to surgery. Mostly balloon angioplasty or valvuloplasty were done with ASD, VSD, or PDA closure., ${ }^{3,4,5}$

We have only faced a single adult case whose VSD and ASD closed in the same session percutaneously. ${ }^{6}$

In conclusion, percutaneous ASD, VSD closure is being done safely in children, but for the first time, percutaneous VSD closure was done in an infant with low body weight in the same session with ASD closure successfully. This case will be an encouraging example for the future.

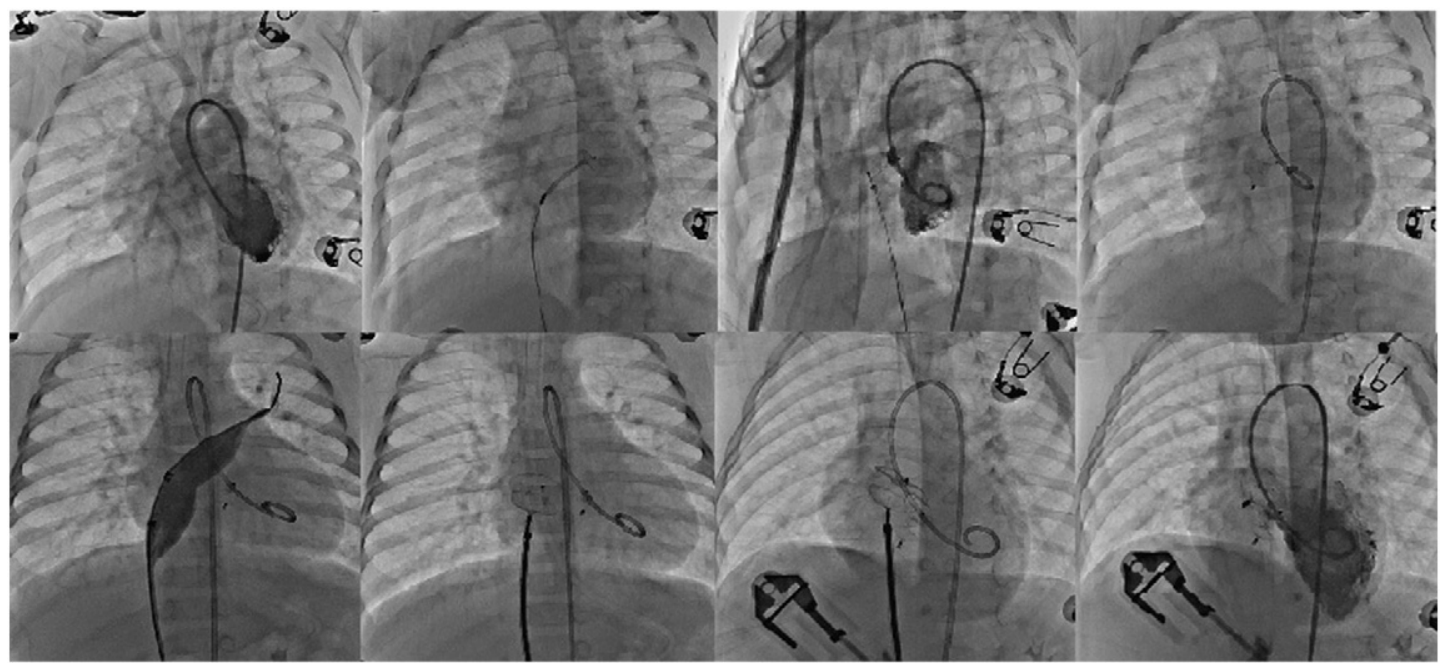

Fig. 2. Percutaneous ASD, VSD closure. 


\section{References}

1. Narin N, Baykan A, Argun M, et al. New modified balloon-assisted technique to provide appropriate deployment in the closure of large secundum atrial septal defect using amplatzer septal occluder in children. J Invasive Cardiol Nov 2014;26(11):597-602

2. Tan CA, Levi DS, Moore JW. Percutaneous closure of perimembranous ventricular septal defect associated with a ventricular septal aneurysm using the Amplatzer ductal occluder. Catheter Cardiovasc Interv 2005;66:427-431.

3. Song ZY, Shu MQ Hu HY, et al. Clinical efficiency and safety analysis of transcatheter interventional therapy for compound congenital cardiovascular abnormalities. Clin Cardiol 2007;30:518-521.
4. Gupta M, Juneja R, Saxena A. Simultaneous device closure of muscular ventricular septal defect and pulmonary valve balloon dilatation. Catheter Cardiovasc Interv 2003;58: 545-547.

5. Ho CL, Fu YC, Jan SL, et al. Combined transcatheter closure of atrial septal defect and patent ductus arteriosus: report of two cases.Combined transcatheter closure of atrial septal defect and patent ductus arteriosus: report of two cases. Acta Paediatr Taiwan 2006;47:197-199.

6. Iyisoy A, Demirkol S, Celik T, et al. Percutaneous transcatheter closure of atrial and ventricular septal defect in the same session. Arch Turk Soc Cardiol 2014;42(3):314. 